\title{
Trabalho infantil em Franca: um laboratório das lutas sociais em defesa da criança $e$ do adolescente
}

\begin{abstract}
Elisiane Sartori ${ }^{* *}$
Resumo

Este artigo propõe uma reflexão sobre o processo de conscientização e mobilização em torno do tema trabalho da criança, as lutas sociais no combate à sua eliminação $e$ o processo de implementação de um dos programas mais atuantes na área o IPEC (Programa Internacional de Eliminação do Trabalho Infantil). Através de um breve retrospecto histórico sobre a entrada do tema trabalho da criança na agenda nacional e internacional, descrevo a atuação dos atores sociais que fizeram parte da discussão e da criação de projetos e de programas de erradicação do trabalho infantil, discutindo a consolidação dos movimentos sociais em defesa das crianças e dos adolescentes. A análise das representações do trabalho infantil na família e no cotidiano das crianças $e$ dos adolescentes está atravessada pela questão de gênero, observada nas falas das crianças e adolescentes, bem como de suas famílias.
\end{abstract}

Palavras-chave: Gênero, Trabalho Infantil, Políticas Públicas, Indústria de Calçados, Franca.

\footnotetext{
" Recebido para publicação em Janeiro de 2006, aprovado em maio de 2006.

** Doutoranda em Ciências Sociais, IFCH/Unicamp. elisiane4@hotmail.com
} 
Trabalho infantil em Franca

Child Labour in Franca:

a Laboratory of the Lute Social in Defensibility of the Children and

Adolescents

\begin{abstract}
This paper proposes a reflection on the process of awareness gain and mobilization around the theme of child labor, the social struggles against the elimination of this practice, and the process of implementation of one of the most active programs in the area the IPEC (International Programme on the Elimination of Child Labour). Through a brief retrospective history of the inclusion of the theme of child labor on both the national and international agendas, this work describes the performance of the social actors participating in the process of discussion and preparation of projects and programs for eradicating child labor. It also discusses the consolidation of the social movements engaged in defending (the rights of) children and adolescents. The analysis of the representations of child labor inside the family and in the daily routine of both children and adolescents is permeated by the gender issue, which is verified in the words of children, adolescents, and their families.
\end{abstract}

Key Words: Gender, Child Labour, Policy Public, Industry of Shoes, Franca. 
Elisiane Sartori

\section{Introdução}

Desde a Revolução Industrial até os dias atuais observamos a presença de milhões de "pequenos" trabalhadores inseridos no mercado de trabalho. No Brasil, e no mundo, há uma diferença entre o mundo que a "criança deveria ter" e o mundo onde ela realmente vive. O primeiro é feito de expressões como "a criança precisa", "ela deve", "vamos lutar para", etc. No segundo, as crianças são orientadas para o trabalho, o ensino $e$ o adestramento físico e moral, restando pouco tempo para a imagem do riso e da brincadeira. A infância é esquecida, o ser criança é deixado de lado, particularmente nas famílias mais carentes, restando somente o trabalho árduo.

De acordo com estudos realizados pelo UNICEF (Fundo das Nações Unidas para a Infância), apesar dos "progressos realizados em todo o mundo no sentido de proteger a criança e garantir seus direitos", chama atenção a exploração do trabalho infantil como um dos piores abusos realizados contra esses direitos. A expressão "trabalho infantil" abrange uma realidade complexa. O trabalho realizado por crianças deve ser analisado como ocorrências registradas ao longo de um continuum: em uma das extremidades é destrutivo, ou envolve exploração, na outra é benéfico, promovendo ou contribuindo para o desenvolvimento físico, mental, espiritual, moral e social da criança, sem interferir em sua educação escolar, sua recreação e seu descanso. ${ }^{1}$

Nas sociedades capitalistas modernas, o trabalho se constitui fora do ambiente familiar e da proteção dos pais, e as crianças

\footnotetext{
${ }^{1}$ Unicef. Relatório da Situação Mundial da Infância, 1997. Em algumas comunidades agrárias, em países subdesenvolvidos, onde o trabalho infantil faz parte integrante do processo de socialização, em que o pai transmite as suas habilidades, conhecimentos e experiências aos filhos, em virtude dos baixos níveis de desenvolvimento tecnológico e baixa eficiência de mão-de-obra, quando se necessita da participação de todos os membros da família tendo em vista satisfazer as necessidades de consumo familiar, o trabalho infantil constitui um elemento fundamental para a sobrevivência da família.
} 
Trabalho infantil em Franca

passam a ser assalariadas ou semi-assalariadas em pequenas oficinas ou em atividades agrícolas, tarefas domésticas ou como trabalhadores domésticos. Mesmo o trabalho executado em ambiente familiar também se transforma, pois passa a exigir de pais e filhos longas jornadas de trabalho, devido à baixa remuneração por produção paga pelos empregadores ou por seus intermediários.

Nesse sentido, o trabalho infantil de "caráter exploratório" se transforma em uma preocupação de âmbito mundial, particularmente no que se refere aos países subdesenvolvidos $e$ em desenvolvimento. Em primeiro lugar, a criança começa a trabalhar cada vez mais cedo (entre cinco e seis anos). Em segundo lugar, o trabalho se estabelece como uma necessidade permanente da criança, o que afeta substancialmente seus estudos, ao contrário dos países desenvolvidos nos quais a criança trabalha em épocas específicas do ano. E, finalmente, as crianças nos países em desenvolvimento trabalham cada vez mais, e com mais freqüência, em condições que afetam seu desenvolvimento físico, psíquico, moral e intelectual.

O tema "trabalho infantil" se constitui como parte da agenda internacional no final do período de reconstrução do pósguerra. Os países em desenvolvimento, que emergiram da era colonial, começam a exigir as mesmas reivindicações que estavam ocorrendo em toda a Europa, com o fito de reconhecimento internacional da necessidade de oferecer atenção especial às crianças. $^{2}$

\footnotetext{
2 A partir disso, o UNICEF foi criado em 1946, com objetivo inicial de dar assistência às crianças, sendo posteriormente ampliado para incluir à sua sobrevivência e ao seu desenvolvimento. $\mathrm{O}$ que existia, até então, era bem pontual, como por exemplo, a Convenção $n^{\circ} 05$, que delimitou em 14 anos a idade mínima para início ao trabalho. Posteriormente, outras convenções $e$ recomendações vieram, contemplando a idade mínima para o início do trabalho $e$ a regularização das condições de trabalho em determinados setores $e$ ocupações.
} 
De acordo com o Relatório da Situação Mundial da Infância de 1997, a Convenção sobre os Direitos da Criança também trouxe profundas mudanças. Ao ratificar a Convenção, o país é obrigado por lei a tomar as medidas adequadas para dar assistência aos pais e/ou responsáveis no cumprimento das obrigações para com as crianças. ${ }^{3}$ No Brasil, os principais movimentos em defesa da criança e do adolescente eclodem entre as décadas de 70 e 80 , quando diversos atores sociais passam a fortalecer o agendamento da questão em âmbito nacional.

Até 1980, a paisagem urbana das grandes e médias cidades apresentava um enorme contingente de crianças perambulando pelas ruas - um espaço de luta e de sobrevivência. Para modificar o tratamento oferecido a este segmento era necessário radicalizar as ações desenvolvidas na área da infância, erradicando os estigmas inseridos no Código de Menores e na FUNABEM (Fundação Nacional do Bem-Estar do Menor) que, ao considerar as crianças como "menores", dificultava suas vidas e fortalecia, ainda mais, os preconceitos existentes no discurso e nas ações da sociedade brasileira.

Por trás desses meninos e meninas existia (e ainda existe) uma deflagração de pobreza instalada no país. Na dura realidade das periferias, zonas rurais depauperadas, a cruel realidade rural brasileira é responsável pela expulsão de milhões de famílias do campo em direção às regiões metropolitanas $e$ às grandes $e$

\footnotetext{
3 Em inúmeros países, novas leis foram aprovadas e leis já existentes foram modificadas para adequar-se à Convenção. Serra Leoa desmobilizou seus soldados infantis, e, em Ruanda, crianças presas em centros de detenção para adultos foram transferidas para instituições específicas para jovens. Iniciativas importantes, como o Congresso Mundial contra a Exploração Sexual de Crianças, realizado em Estocolmo, em agosto de 1996, e a Conferência Internacional sobre o Trabalho Infantil, programada para outubro de 1997, em Oslo, resultam de energia mobilizada pela Convenção. Atualmente, $96 \%$ das crianças em todo o mundo vivem em estados que estão legalmente obrigados a protegerem seus direitos. (Relatório Anual da OIT, 1999)
} 
Trabalho infantil em Franca

médias cidades. ${ }^{4}$ A compreensão desses fatos necessitava de uma abordagem inovadora da questão do atendimento a meninos e meninas de rua, que apontasse para o começo de um processo de reversão da política brasileira de atendimento aos direitos da infância e da juventude $e^{5}$, processo que desencadeou a criação do DCA (Fórum Nacional Permanente de Entidades Não-Governamentais de Defesa dos Direitos da Criança e do Adolescente) em março de $1988 .{ }^{6}$ O Fórum surgiu da necessidade das entidades representativas constituírem um organismo permanente que organizasse a participação na Constituinte $e$ desenvolvesse ações conjuntas no combate à violência contra a infância pobre, tornando-se o principal interlocutor da sociedade civil no que se refere à questão da criança e do adolescente no Brasil. $^{7}$

${ }^{4}$ Costa, Antônio Gomes da. O Estatuto da Criança e do Adolescente e o Trabalho Infantil. São Paulo, Editora LTr, 1994.

${ }^{5}$ Nesse sentido, foi organizado, em nível nacional, um amplo movimento em defesa dos meninos e meninas de rua com o intuito de erradicar a forma de tratamento discriminatória e estigmatizante. Nesse período, foram criadas Comissões Locais, depois Comissões Estaduais e estas, finalmente, elegeram em 1985, a Coordenação Nacional do Movimento Meninos e Meninas de Rua que foi, sem sombra de dúvida, o evento e a conquista mais importante na área da infância vista até então no Brasil.

6 DAgnino, Evelina. Os Movimentos Sociais e a Emergência de uma Nova Noção de Cidadania. In: Os Anos 90: Política e Sociedade no Brasil. São Paulo, Brasiliense, 1995.

7 Reunindo todos estes esforços e contando com a participação decisiva de vários parlamentares comprometidos e sensibilizados com a "questão do menor", a emenda Criança Prioridade Nacional foi incluída na sua quase totalidade, particularmente no artigo 227 da Constituição Federal de 1988, sendo a primeira Constituição em nosso país a garantir direitos específicos à criança $e$ ao adolescente. O Artigo 227 manifesta a postura do movimento social ao reafirmar que "é dever da família, da sociedade e do Estado assegurar à criança $e$ ao adolescente, com absoluta prioridade, o direito: à vida, à saúde, à alimentação, à educação, ao lazer, à profissionalização, à cultura, à dignidade, ao respeito, à liberdade, à convivência familiar e comunitária. Além de colocá-los a salvo de toda forma de: negligência, discriminação, exploração, violência, crueldade, opressão". 
Quando nos remetemos à questão de gênero, verificamos que a maioria são meninos de rua. No contexto social de onde se originam, as mães trabalham fora $e$ as meninas têm como tarefa cuidar dos irmãos menores e arrumar a casa. ${ }^{8}$ Gênero é aqui entendido como um elemento constitutivo de relações sociais, baseado nas diferenças percebidas entre os sexos. Desse modo, percebe-se que gênero é um primeiro modo de dar significado às diferenças e que tais diferenças são produzidas socialmente, não sendo meras distinções anatômicas, marcas biológicas indeléveis do sexo. Tais diferenças não são apreendidas como pluralismos e, sim, operadas como desigualdades, que se manifestam no cotidiano. Ao rejeitar o determinismo biológico - que busca a sujeição da mulher em sua capacidade reprodutiva ou na força física masculina - gênero enfatiza as qualidades sociais das distinções baseadas no sexo. É uma categoria relacional que define homens e mulheres uns em relação aos outros. ${ }^{9}$

Nesse contexto, o trabalho infantil entrou para a agenda de diversos setores da sociedade brasileira também como uma forma de entender como gênero opera nas várias ocupações existentes em nossa sociedade, a princípio, nas ONG's direcionadas à defesa da infância, estendendo-se progressivamente a inúmeras organizações do movimento social nacional. Um dos grandes marcos da introdução do tema na agenda é a implantação do Programa Internacional para a Eliminação do Trabalho Infantil, criado pela OIT em 1992. Logo, o trabalho infantil adquiriu status de questão social, tornando-se objeto de esforços específicos, articulados e significativos, desempenhados através de parcerias estabelecidas entre organizações governamentais $e$ nãogovernamentais, órgãos multilaterais, entidades da sociedade civil e instituições do setor privado.

8 FRAngella, Simone Miziara, Fragmentos de corpo e gênero entre meninos e meninas de rua. Cadernos Pagu (14), Núcleo de Estudos de Gênero Pagu/Unicamp, 2000, pp.201-234.

9 ScotT, Joan W. Gênero: uma categoria de análise histórica. Educação e Realidade, n 2, Porto Alegre, jul./dez. 1990. 
Trabalho infantil em Franca

À luz dessas entidades, preocupadas com a erradicação do trabalho infantil, este artigo discute como se dá a inserção das "crianças" no trabalho, buscando entrelaçar as falas dos pais, das crianças e das organizações que se empenham nesta luta na cidade de Franca.

\section{O trabalho infantil na indústria de calçados de Franca/SP}

A inserção das crianças em ocupações onde proliferam as denominadas "bancas de pesponto" e a "costura doméstica" ambientes clandestinos - está associada a características do processo de terceirização existente na produção de calçados, revelando o caráter precário da utilização da mão-de-obra infantil. Embora o trabalho infantil não seja realizado diretamente nas indústrias de calçados, devido, dentre outros fatores, a proibição legal instituída pelo $\mathrm{ECA}^{10}$, este tipo de trabalho mantém-se no espaço doméstico, sofrendo o controle da própria família.

A família é a primeira e uma das principais instituições que reproduz determinadas regras sociais, dentre elas, as caracterizações de gênero, colocando os sexos em oposição $e$, muitas vezes, estimulando a desigualdade. Essas caracterizações reproduzem na sociedade as relações de poder e comportamentos de meninas e meninos. A ruptura dessas concepções é dificultada pela legitimação e valoração das diferenças, que abrangem relações entre pai-filho, mãe-filho $e$ irmãos, bem como diferenciações entre tarefas domésticas $e$ trabalhos realizados dentro e fora de casa.

No caso do trabalho infantil disseminado no município de Franca, onde toda a família se envolve na fabricação de calçados, o menino e a menina são inseridos de uma forma ou de outra dentro do processo produtivo. A criança, desde de muito cedo, colabora costurando ou colando pares de sapato que a mãe

${ }^{10}$ Estatuto da Criança e do Adolescente, marco no sistema de legislação em defesa da erradicação do trabalho infantil e de combate à exploração do adolescente trabalhador, da América Latina. 
recebe do intermediário, da fábrica ou das associações de costureiras de calçados, trabalhando durante horas no próprio ambiente doméstico. Além disso, crianças e adolescentes também trabalham nas bancas de pesponto, em ambientes insalubres, ganhando salários baixos, realizando tarefas denominadas "serviços de mesa" - colar, dobrar e aparar as peças de couro que vão compondo o sapato.

A menina não é preservada do trabalho, ao contrário, além de auxiliar no trabalho de pesponto ainda tem que ajudar a mãe nas tarefas domésticas, configurando-se dupla jornada de trabalho desde a mais tenra idade ${ }^{11}$, conforme salienta uma das mães entrevistadas: "...minha filha tem que trabalhar mesmo, o que eu ganho não serve nada, e, além disso, tem que me ajudar em casa, é mulher, precisa aprender a fazer as coisas desde cedo".

Nesse sentido, de um lado, existem famílias sem recursos financeiros, desassistidas e sem atendimento das políticas sociais públicas, tendo como alternativa última a inclusão de seus/suas filhos/as no mercado de trabalho. De outro, as crianças passam a ser inseridas no mundo do trabalho pelo próprio grupo familiar, como uma passagem normal e como símbolo de aprendizagem, obediência e disciplina, sendo constituída em alternativa primeira e básica para o próprio aprimoramento da criança. ${ }^{12}$

No início dos anos 90, Franca tinha um alto índice de crianças trabalhadoras em bairros periféricos, sentadas nas calçadas de suas casas; mães e filhos/as costurando sapatos e, dentro das residências, grupos de pessoas trabalhando em torno de uma máquina de pesponto; ao mesmo tempo, a cidade apresentava uma significativa parcela de crianças $e$ adolescentes trabalhando em "serviços de mesa" em bancas de pesponto,

${ }^{11}$ Para saber mais sobre a questão da "dupla jornada feminina", ver DAL-Rosso, Sadi \& RESENDE, Maria Lúcia S. Comerás o pão com o suor do teu rosto - as condições de emprego do menor trabalhador. Thesaurus, 1986.

${ }^{12}$ PereIRA, Irandi. Trabalho Infantil: Mitos e Dilemas. Dissertação de Mestrado, Faculdade de Educação/USP, 1999. 
Trabalho infantil em Franca

expostos a solventes orgânicos, ambientes pequenos, mal ventilados, recebendo salários ínfimos. ${ }^{13}$

Esse quadro começa a se reverter a partir de 1992, com a instalação do Programa Internacional de Eliminação do Trabalho Infantil - IPEC/OIT. O processo de conscientização e de mobilização da sociedade francana em defesa da criança e do adolescente ocorreu de forma bastante peculiar e progressiva. É interessante destacar uma certa mobilização, ainda que tímida, do Sindicato dos Trabalhadores das Indústrias de Calçados de Franca, que atuava diretamente com a questão da criança e do adolescente $^{14}$ pela ótica do direito, outras instituições se circunscreviam no raio de atuação assistencialista e filantrópica, mas sofrem modificações com o advento do Estatuto da Criança $e$ do Adolescente.

Embora o trabalho da criança estivesse na pauta de discussão, o poder público tinha uma visão de inclusão social das crianças pertencentes às famílias carentes por meio do trabalho. Essa atitude está relacionada ao processo histórico de Franca, que sempre admitiu e legitimou a incorporação da mão-de-obra infantil como um fato "normal", idéia predominante nas instituições, na imprensa, nos diversos segmentos que atuavam na

${ }^{13}$ De acordo com o relatório da FUNDACENTRO (Fundação de Segurança e Medicina do Trabalho), o solvente $\mathrm{n}$-Hexano, empregado na indústria de calçados, tanto na colagem como na limpeza do calçado, pode levar ao surgimento das "polineuropatias periféricas", doenças que se instalam preferencialmente no sistema nervoso periférico, podendo causar "astenia, parestesia, câimbras musculares, até completa tetraparesia". Fundacentro, jan/1991.

${ }^{14} \mathrm{O}$ Sindicato dos Trabalhadores das Indústrias de Calçados de Franca, desde sua fundação em 1982, tem se constituído na liderança de maior destaque no cenário político-sindical local. Representa a categoria profissional mais numerosa da cidade, contando com aproximadamente 35 mil trabalhadores, dos quais 14 mil são filiados ao Sindicato (CUT, 1994). A sua atuação se faz por meio de três eixos básicos: Campanha Salarial, Imprensa Sindical e Educação Política. Suas atividades são distribuídas em secretarias específicas, como de Organização, de Saúde, de Formação Política, de Imprensa, do Esporte, do Lazer e da Cultura, onde se busca alcançar uma forma de gestão mais democrática e participativa. 
cidade, no interior dos grupos familiares, incluindo trabalhadores e empresários, além dos pais e das mães, que consideravam comum o fato das crianças trabalharem, pois estavam "aprendendo uma profissão, não permanecendo nas ruas se drogando, com más companhias". O valor cultural do trabalho era (e ainda é) muito enraizado. Apesar dos pais constituírem uma pequena parcela dos entrevistados, suas falas apontam para a aceitação quase imediata do trabalho de seus/suas filhos/as, valendo-se da justificativa de também terem começado a trabalhar desde muito cedo.

$\mathrm{O}$ orçamento familiar restrito induz todos os membros da família ao trabalho sem distinção de sexo, mas há uma visível diferença entre as falas das mães e pais atendidos por programas sociais em relação às famílias não atendidas. As mães participantes de programas assistenciais admitem fazerem de tudo para os seus/suas filhos/as não trabalharem, no sentido de aproveitarem ao máximo o período dedicado à escola. Os/as pais/mães não atendidos admitem colocarem os filhos/as no trabalho em caso de necessidade financeira e dão "graças a Deus" por eles/as gostarem de trabalhar.

Os pais/mães atendidos, em sua grande maioria, admitem 14 e 16 anos uma idade "boa" para iniciarem o trabalho. As famílias não atendidas por programas apontam 10 e 14 anos como a idade de assumir parte do orçamento doméstico, independente de serem meninos ou meninas. Portanto, pais e mães concordavam que o trabalho é uma forma de aprendizagem para a vida de seus/suas filhos/as, principalmente àqueles não conscientizados dos malefícios que o trabalho traz para a vida das crianças.

As entidades assistenciais existentes no município admitiam, também, o trabalho das crianças como pré-requisito para a inserção no mercado de trabalho. O discurso dos empresários não enxergava o trabalho das crianças como algo ruim e prejudicial, mas uma forma de disciplinização, o que servia de pretexto para encobrir o verdadeiro sentido exploratório da ação. 
Trabalho infantil em Franca

Essa situação se agrava com o trabalho da criança e do adolescente na indústria de calçados, pois ao envolver a família a exploração é feita de forma mais sutil e descentralizada. No bojo do processo de "terceirização" nas indústrias, no final dos anos 80 , a precarização das relações de trabalho transfere o trabalho de dentro das indústrias para dentro das residências, o que era $(e, e m$ parte, ainda é) totalmente aceito e legitimado pela sociedade. Esse "bem-estar" derivava do bom desempenho da indústria de calçados: o fato de as crianças sempre ter participado desse processo de trabalho tornava uma "situação quase natural" sua permanência, dada a demanda de mão-de-obra na cidade e na região.

Em 1989, o Sindicato dos Trabalhadores da Indústria de Calçados de Franca (conhecido como "Sindicato dos Sapateiros") iniciou o monitoramento nas indústrias e, percebendo o aumento da utilização de mão-de-obra infantil, fez uma tentativa, fracassada, de chamar a sociedade para discutir o problema, o que os levou a buscar parcerias com agentes externos à cidade, com intuito de diagnosticar a demanda, a necessidade e os malefícios dessa incorporação precoce. ${ }^{15}$

Dessa maneira, foi realizado um estudo de caso preliminar "Estudo de Caso de Crianças Trabalhadoras no Setor de Calçados de Franca"16 -, cujo resultado constatou uma grande parcela das crianças e dos adolescentes trabalhadores da "banca de pesponto" sem registro na Carteira Profissional, exceto aqueles que

15 Chama atenção o fato de que já no início da década de noventa, a indústria de calçados não se encontrava em uma situação econômica tão favorável. Em meio a este cenário, o tema trabalho infantil entra em discussão - em 1992 - em decorrência da aprovação do estudo de caso realizado em parceria da Central Única dos Trabalhadores (CUT) com IPEC/OIT/Brasil.

${ }^{16}$ Destaca-se neste primeiro estudo o projeto "Orientação de crianças trabalhadoras na indústria e outros setores: capacitação de sindicalistas $e$ conscientização da sociedade", convênio IPEC/OIT e CUT. 
conseguiram autorização no Juizado da Infância e da Juventude. ${ }^{17}$ Esse fato reflete uma incoerência diante ao Estatuto da Criança $e$ do Adolescente, que proibia o trabalho aos menores de 14 anos, salvo na condição de aprendiz. ${ }^{18}$ A partir desses dados, o "Sindicato dos Sapateiros" assume o tema trabalho infantil como uma de suas prioridades na agenda sindical - estabelecido pelo convênio CUT/OIT/IPEC.

A divulgação dessa pesquisa pela imprensa local e nacional aumentou a demanda de outros setores no Sindicato, com repercussões que variaram do apoio consciente e fortalecedor, até críticas acirradas sobre o tema. Os resultados desse estudo de caso propiciaram uma pesquisa mais aprofundada - também em parceria com a CUT, Sindicato dos Trabalhadores da Indústria de Calçados de Franca e DIEESE, com apoio do UNICEF e OIT/IPEC no interior das escolas públicas (estadual e municipal) para mapear os focos de trabalho infantil. Outro objetivo da pesquisa era identificar o trabalho doméstico com vistas a conscientizar a população com relação ao número de crianças trabalhadoras $e$ suas condições de trabalho.

A pesquisa "Crianças que Estudam e Trabalham em Franca" - realizada entre 1993/94, onde foram entrevistadas 1561 crianças entre 07 e 13 anos - identificou que a maior parte das crianças $(73 \%)$ trabalhava na produção de calçados. Os outros setores econômicos não alcançavam nem $10 \%$ das atividades desempenhadas pelas crianças, por exemplo, a guarda-mirim. Além de comprovar o alto índice de "trabalhadores mirins", a pesquisa mostrou que as condições de trabalho eram

\footnotetext{
${ }^{17}$ Durante o ano de 1992, a autorização do Juizado da Infância e da Juventude foi concedida a 347 adolescentes de 13 e 14 anos e, em janeiro de 1993, a 50, de acordo com o Serviço Social de Menor do Fórum local.

${ }^{18}$ Atualmente, o ECA proíbe o trabalho aos menores de 16 anos, salvo na condição de aprendiz.
} 
Trabalho infantil em Franca

extremamente precárias, recebendo salários baixos (quando recebem) e com elevada jornada de trabalho. ${ }^{19}$

A divulgação dos dados da pesquisa levou a uma maior conscientização da sociedade francana. Nesse momento, a indústria calçadista em Franca começa a perder com a redução da exportação. Pari passu a essa série de fatos, o país passava por um momento de reestruturação produtiva - abertura do mercado, busca de produtividade, redução dos custos de trabalho, etc. -, propiciando a criação de espaços de discussões inovadores $e$ atuantes em Franca. O IPEC, um dos atores fundamentais neste processo de sensibilização e conscientização da sociedade, propiciou a entrada de diversos atores sociais na discussão sobre o trabalho infantil no Brasil, particularmente em Franca. ${ }^{20}$

\section{Combate ao trabalho infantil em Franca e a participação da família}

O IPEC/OIT teve como instituição executora no município de Franca a Central Única dos Trabalhadores (CUT), tendo como um dos seus principais parceiros o UNICEF (Fundo das Nações Unidas para a Infância). A formação de uma unidade de ação conjunta entre a OIT e o UNICEF vai se desenvolvendo durante todo o processo de implementação do IPEC/Franca, com áreas e formas de atuação diferentes, mas trocando informações e exercendo um trabalho de articulação. A relação entre os dois organismos multilaterais, em nível nacional e internacional, define-se por duas linhas específicas de ação: um trabalha muito mais no sentido de diagnosticar (OIT) e o outro no sentido de intervenção e de criar

\footnotetext{
${ }^{19}$ De acordo com dados da pesquisa realizada, no final de 1994 existiam em Franca, cerca de cinco mil crianças e adolescentes trabalhando no processo de terceirização, seja nas bancas de pesponto ou nas próprias residências.

${ }^{20}$ O IPEC foi criado pela OIT em 1991 como forma de unir esforços para, numa ação conjunta, combater progressivamente o trabalho infantil e eliminar a exploração do trabalho dos adolescentes, através do fortalecimento da capacidade nacional de lidar com o problema. Para tanto, o ponto de partido do Programa é a vontade política.
} 
referência, especialmente na área da educação (UNICEF), definindo-se caracteristicamente como atividades complementares.

$\mathrm{O}$ primeiro projeto realizado em Franca em parceria com o IPEC/UNICEF foi um trabalho conjunto com o Sindicato dos Trabalhadores das Indústrias de Calçados de Franca de formação profissional dos adolescentes. Num segundo momento, o projeto passou a abranger, também, as crianças, resultando no programa "Combatendo o Trabalho Infantil - Bolsa-Educação". ${ }^{21}$

A metodologia do trabalho utilizada corresponde aos estudos de avaliação de implementação de programas sociais, tendo como foco de análise o seu funcionamento através das diversas etapas, dos mecanismos e das conexões causais existentes na implantação de programas sociais.

Tal estudo geralmente centra-se nas seguintes questões: 1) o que acontece no funcionamento do programa? 2) os resultados gerados pelo programa realmente decorrem do programa? 3) como os resultados alcançados pelo programa estão associados a componentes específicos? 4) quais os pontos de estrangulamento do programa? 5) quais são as relações institucionais necessárias para colocar o programa em funcionamento? 6) os mecanismos de

${ }^{21}$ Com relação à família, o Programa proporciona o pagamento de uma bolsa mensal, caracterizada como "bolsa familiar", tendo como contrapartida a entrada da criança e/ou adolescente na escola. Atualmente, são atendidas cerca de 180 famílias, e cada uma recebe $\mathrm{R} \$ 100,00$ ao mês, um valor fixo. No que se refere à criança, há um acompanhamento do desenvolvimento curricular e da freqüência escolar. Caso a criança e/ou adolescente não freqüente nenhuma atividade complementar oferecida pela escola, ela participa de atividades complementares oferecidas pelo Programa que abrange capoeira, educação física, educação artística, teatro e dança. Em relação à escola, o Programa interfere quando ocorre falta de equipamentos, de material escolar e, também, atua na capacitação pedagógica dos professores. Atualmente, o Programa atende 180 famílias, como citado anteriormente, sendo 58 famílias na região norte e 122 famílias na região sul. Os recursos são financiados pela Prefeitura Municipal de Franca, desde abril de 1997, por meio da Secretaria da Assistência Social. O UNICEF, hoje, fornece um apoio técnico-financeiro direcionado às despesas referentes à capacitação dos professores e aos projetos de geração de renda às famílias. 
Trabalho infantil em Franca

operação do programa funcionam como originalmente concebido pelos formuladores? A avaliação de processo verifica se o funcionamento do programa está ocorrendo de acordo com o planejado, buscando levar em conta a sua repercussão imediata entre usuários e beneficiários, priorizando as dimensões e os fatores condicionantes do fracasso ou do sucesso de sua implementação. ${ }^{22}$

$\mathrm{O}$ interesse pelas representações sociais tornou-se imprescindível no processo de avaliação metodológica da pesquisa, tornando-se o meio pelo qual a subjetividade pode ser pensada nas ciências sociais. Na Sociologia correspondeu ao esforço de pensar o inconsciente e a ideologia na explicação das condutas ou, ainda, como aponta Pierre Bourdieu, de restituir à subjetividade, passando a ser uma forma privilegiada de pensar a relação entre o material e o mental na evolução da sociedade. ${ }^{23}$ Essa vertente prioriza o processo social ao qual as representações se formam $e$ se transformam e é nessa perspectiva que descrevemos e analisamos, de forma sucinta, as representações das famílias das crianças trabalhadoras.

A representação e/ou a efetividade do programa IPEC/ OIT/UNICEF na vida das famílias entrevistadas demonstra sua importância na dinâmica intrafamiliar. As atividades complementares à escola - aulas de capoeira, educação física, educação artística, passeios, etc -, bem como os cursos de geração de renda às famílias foram apontados como essenciais no

${ }^{22}$ De acordo com estes princípios metodológicos, a pesquisa foi realizada através da elaboração de um "estudo de caso", a partir da seleção de dois grupos de criança e adolescente e respectivas famílias. O primeiro grupo foi formado por crianças/adolescentes e pais e/ou mães pertencentes à classe social de baixa renda, atendidas pela parceria IPEC/OIT/Brasil/Franca e UNICEF/Brasil, no qual se tenha verificado uma sensível diferença em relação ao modo de vida, incluindo a adesão das crianças e dos adolescentes à escola. O segundo grupo formado também por crianças/adolescentes e pais e/ou mães com perfil sócioeconômico semelhante, mas que nunca participaram do programa IPEC/OIT/Brasil/UNICEF/Franca/SP, constituindo a demanda reprimida.

${ }^{23}$ Pierre Bourdieu apud Jodelet. 
combate ao trabalho da criança e na própria mudança de vida das crianças e dos adolescentes. Vale ressaltar, porém, que tanto os pais quanto às mães admitem que há um excesso de brincadeiras durante as atividades complementares que, no caso dos adolescentes, poderiam ser transformadas em cursos profissionalizantes. A preocupação central de ambos é sempre a possibilidade dos/as adolescentes se prepararem para enfrentar um mercado de trabalho tão acirrado como se caracteriza o nosso. Os pais e/ou mães admitem que o Programa trouxe muitos benefícios para os seus/suas filhos/as, mas no quesito profissionalização deixou muito a desejar.

A retirada das crianças do trabalho e a permanência na escola como critério para a inserção das famílias no programa, objetivo central do programa, foi considerado essencial pelas famílias, pois permitiu que as crianças deixassem o trabalho penoso e exploratório. A escola, mencionada pelos pais e/ou mães como de grande valia à aprendizagem $e$ ao aprimoramento intelectual de seus filhos, é considerada um dos principais meios de ascensão social, pois admitem que os estudos podem oferecer às crianças um "futuro melhor" em comparação ao que eles tiveram.

O trabalho infantil em Franca faz parte da história da cidade, em especial no processo de fabricação de sapatos, na medida em que o serviço passa de pai para filho. Mudar essa maneira de pensar o tema e fazer com que os pais entendam os malefícios do trabalho para a vida da criança foi extremamente complicado e dificultoso. Os "novos pais", configurados no contexto de erradicação do trabalho infantil, acreditam que a escola é a porta de entrada para uma boa oportunidade profissional na vida de seus filhos e lutam para que isso ocorra. Apesar de terem se conscientizado de que existem outras formas de geração de renda, sem precisar colocar os filhos para trabalhar, esse processo foi lento e gradual; se a valorização cultural do trabalho predomina até hoje no município, ela é mais tênue. 
Trabalho infantil em Franca

Tanto o pai quanto a mãe não-conscientizados não diferenciam o trabalho realizado por sexo, o importante é que tragam o dinheiro para a casa:

...eu acho que trabalhar em 'banca de pesponto' é errado, mas tem muita criança que trabalha para ajudar os pais, agora trabalhar colando sapato não tem nada de mais, eu acho bom porque mantém os/as filhos/as dentro de casa, não fica na rua fazendo malandragem.

Além da contribuição financeira, o trabalho da criança serve para livrar os pais de uma preocupação, por exemplo, o envolvimento com drogas.

A maioria das famílias não atendidas pelo programa de combate ao trabalho infantil se encontra numa situação econômica bastante difícil - desempregadas, fazendo "bico", com apenas um membro da família trabalhando. Portanto, o que lhes resta é trabalhar na confecção de sapatos (costura manual $e$ colagem de enfeites) dentro das próprias residências. Nesse processo, todos os membros da família (pais, mães e filhos) trabalham juntos para aumentar a renda, pois o valor por produção final de sapato é muito baixo. ${ }^{24}$ Nesse sentido, é quase unânime a idéia de que se não receberem ajuda financeira, não há como retirar as crianças do trabalho.

Nesse contexto, a escola - classificada como ótima e muito boa por todos os entrevistados - surge como uma alternativa para as crianças e os adolescentes no sentido de obter melhores oportunidades profissionais; mesmo "ajudando" os pais na confecção dos calçados, as crianças freqüentam a escola regularmente. Se é difícil encontrar crianças trabalhando em "bancas de pesponto", em razão da fiscalização, no período em que não estão na escola, as crianças e/ou adolescente auxiliam os pais, vizinhos ou amigos na costura manual de sapato. A maior

${ }^{24} \mathrm{O}$ valor estimado é de $\mathrm{R} \$ 0,30$ a $\mathrm{R} \$ 0,40$ por par de sapato acabado. 
parte dos pais e/ou mães acham importante, bom e rentável que seus/suas filhos/as trabalhem, não enxergando nenhum tipo de malefício - mesmo quando seus filhos trabalham cerca de 08 a 10 horas diárias. Para as famílias, trata-se de uma forma de apreender um ofício e, concomitantemente, auxiliar nas despesas domésticas. O ritmo acelerado do trabalho das crianças e a destreza das mãos pequenas parecem ser fatores que influencia os pais a requisitar o trabalho das crianças que, pela própria agilidade, aumenta a produtividade.

É mais difícil encontrar crianças trabalhando nas ruas, nas bancas de pesponto, nas praças, devido às denúncias $e$ ao processo de mobilização na sociedade francana no combate ao trabalho infantil referente ao processo de terceirização da indústria de calçados, no entanto, houve um deslocamento do trabalho infantil das "bancas de pesponto" para dentro lar - na cozinha, na sala - o chamado "processo de quarteirização" da produção de calçados, dificultando a fiscalização. Nesse sentido, o trabalho da criança ainda representa, para esses pais, uma forma de aprendizado e de adquirirem responsabilidade, para que a criança não permaneça na "rua", apresentada como um espaço marginal $e$ de aprendizagens negativas para o seu desenvolvimento moral.

De forma distinta, os pais atendidos pelo programa IPEC/OIT/UNICEF, quando perguntados sobre a importância do trabalho na vida de seus filhos, reforçam a idéia de que estudar e o lúdico na vida de seus filhos são imprescindíveis para a sua formação. Essas afirmações apontam para a importância dos programas de subsídio às famílias, no sentido de eliminar a exploração da mão-de-obra infantil.

\section{As crianças e suas representações}

O trabalho realizado com crianças e adolescentes assumiu um método de investigação dinâmico, permitindo captar as representações das crianças num processo que estimula a reflexão e a crítica da situação vivenciada. O referencial teórico que 
Trabalho infantil em Franca

embasa esta metodologia pauta-se pela dialética que reconhece a importância da estrutura econômica e social no entendimento dos fenômenos. De acordo com Minayo, a dialética refere-se ao método de abordagem real enfatizando, na análise, as articulações entre as idéias $e$ a base material $e$ entre o indivíduo $e$ a sociedade. ${ }^{25}$

As crianças e/ou adolescentes atendidos pelo programa IPEC/OIT/UNICEF enfatizam as atividades complementares, considerada de suma importância para o processo ensinoaprendizagem ao qual estão inseridas, além de propiciarem sua retirada da rua e do "não fazer nada". A escola, nesse sentido, é visualizada como fundamental no processo de formação e tida como preferência primeira na escolha das crianças pelos estudos, o que vai de encontro ao pensamento dos pais participantes do programa.

O histórico das crianças entrevistadas é de trabalho infantil, passando por várias funções: babá, pedreiro, capinar terreno, carregador de saco de cal em depósito de construção civil e a grande maioria na confecção de sapatos, em suas casas ou em "bancas de pesponto" (os adolescentes), recebendo salários extremamente baixos.

Tanto as meninas quanto os meninos se envolvem da mesma forma na produção de calçados dentro de suas casas. Se a família ganha pouco e não recebe nenhum tipo de auxílio assistencial - governamental ou não -, desde muito cedo as crianças são chamadas a participar do orçamento doméstico. Quando não estão na produção de calçados, as tarefas dos meninos se direcionam mais para empacotador de supermercado, "olhar carro", auxiliar de feira livre, etc. As meninas, quando não estão trabalhando na costura de sapatos, realizam tarefas domésticas dentro de suas próprias casas, da vizinhança ou de parentes. Além disso, elas também cuidam de seus irmãos menores ou trabalham de babás.

${ }^{25}$ MinAYO, 1993. 
As relações de gênero que organizam a desigualdade social entre homens e mulheres $e$ os lugares ou espaços também adquirem valorizações e significações desiguais, gerando ocupações, tarefas e responsabilidades sexuadas. Relações de gênero materializam relações de poder, apoiadas em assimetrias, revestidas de aparente consenso, apesar das contradições, conflitos e resistências que as perpassam. ${ }^{26}$

As falas das crianças apontam para um consenso no que se refere a trabalhar e/ou estudar. A primeira é de um menino extrabalhador atendido pelo IPEC, a segunda é de uma menina trabalhadora pertencente a uma família de baixa renda que não recebe nenhum tipo de auxílio assistencial:

...eu já trabalhei, não era bom, atrapalhava meus estudos, tinha que acordar cedo, dava muito sono dentro da sala de aula, não conseguia aprender a lição direito. Eu acho uma falta de vergonha os pais colocarem seus filhos para trabalharem.

...eu acho que nós deveríamos ter um tempo para brincar e estudar. Eu não sei, chega na escola tá com dor nas mãos, nas costas, cansada de tanto costurar sapato.

Dessa forma, percebemos que ambas crianças preferem estudar e brincar do que se envolver com tarefas que elas próprias consideram de adultos. Independente do sexo, da idade, das condições sócio-econômicas, criança quer ter o direito de ser criança.

No geral, o significado do trabalho em suas vidas é apresentado como ruim; cansaço físico, desânimo, dores de cabeça, sono, dores nas mãos são sintomas apontados com freqüência pelas crianças que já trabalharam.

${ }^{26}$ Duque-ARRAzola, Laura Suzana. O cotidiano sexuado de meninos e meninas em situação de pobreza. In: MADEIRA, Felícia Reicher. (org.) Quem mandou nascer mulher?: estudos sobre crianças e adolescentes pobres do Brasil. São Paulo, Rosa dos Tempos/ UNICEF, 1997. 
Trabalho infantil em Franca

As crianças e os adolescentes demonstraram-se bastante satisfeitos com a participação no programa, sendo que a chegada do "Bolsa-Educação" ao município mudou de imediato suas vidas. A saída do trabalho é apontada como responsável pela diminuição da ocorrência de brigas na família e com os colegas, além de proporcionar melhor desenvolvimento físico, psíquico e social. Estes fatos apontam para a eficácia desses programas centrados na criança, na escola e na família - no combate ao trabalho da criança em todo o país, um conjunto de intervenções que favorece a melhor qualidade de vida às familias $e$, conseqüentemente, uma integração entre escola e criança.

No contraponto, apresento algumas reflexões sobre as crianças não atendidas pelo programa IPEC/OIT/UNICEF. Houve consenso no que diz respeito à vontade de se inserirem imediatamente no programa, pois imaginam que este lhes trará melhor qualidade de vida e uma melhoria no processo ensinoaprendizagem, a partir das atividades complementares que o programa oferece, principalmente em decorrência da oportunidade de pararem de trabalhar.

A maioria das crianças e/ou adolescentes entrevistados trabalham em suas residências, auxiliando seus pais na confecção de sapatos. Houve conscientização do trabalho na "banca de pesponto", tido como ruim e ilegal, mas nada impede que as crianças continuem trabalhando em suas residências ou mesmo prestando serviço em residências vizinhas ou de amigos. Apesar de cientes dos malefícios que o trabalho traz às suas vidas - atraso escolar, baixo desenvolvimento intelectual, prejuízo à saúde, perda de liberdade, perda do lazer e da brincadeira, cansaço físico e mental - as crianças vivem o conflito "estudar x trabalhar" - o desejo de se dedicarem somente aos estudos é sucumbido pela necessidade de trabalhar.

Comparando com as crianças atendidas pelo programa IPEC/OIT/UNICEF, percebe-se uma discrepância até com relação ao acesso às oportunidades. $\mathrm{O}$ cansaço produzido pelo trabalho de várias horas durante o dia aparece como um fator que dificulta 
a aprendizagem. Essa criança, menos preparada para um mercado de trabalho acirrado e competitivo, enfrentará dificuldades em conseguir empregos qualificados, com maiores salários, restando-lhe trabalhos precarizados, favorecendo o "círculo vicioso da pobreza", que se perpetua de geração em geração.

\section{Considerações finais}

A questão do trabalho infantil, no mundo e no Brasil, emerge com vigor no início da década de 90 a partir de uma série de denúncias, resultando na sensibilização, conscientização $e$ mobilização da sociedade brasileira. $\mathrm{O}$ conjunto de atores que propiciaram a discussão e a difusão do tema fez com que a erradicação do trabalho infantil passasse por um processo mais amplo do que simples ações pontuais. A ampliação dessa pauta levou ao questionamento mais vigoroso da exploração vergonhosa de milhões de pequenos trabalhadores. Nesse cenário de luta pela defesa dos direitos da criança e do adolescente, a implantação o IPEC proporcionou uma ação conjunta de diversos atores na consolidação de uma política pública nacional de combate à exploração da mão-de-obra infantil em nosso país.

Se Franca - uma das regiões mais ricas do país - se destaca como um município atendido pelo Programa, por que em uma cidade, onde o padrão de vida dos moradores é maior em relação a outras cidades ${ }^{27}$, situada na denominada "Califórnia Brasileira", onde predomina uma indústria dinâmica, exportadora e competitiva, ocorre a existência da utilização da mão-de-obra infantil?

Primeiro, devido ao processo de empobrecimento que vem ocorrendo no Brasil em geral, e no município em particular, desde o final dos anos 80 , resultante da combinação de arrocho salarial,

${ }^{27}$ A renda familiar média de Franca é de quatro salários-mínimos, ao passo que no país essa renda está em torno de meio salário-mínimo (IBGE, 1991). 
Trabalho infantil em Franca

aumento da precarização do trabalho e da informalidade (com o advento do processo de terceirização da produção), aumento do desemprego. Essa situação levou ao acirramento da utilização de mão-de-obra infantil, mantendo-se as condições propícias para esse tipo de exploração. Um outro aspecto relevante é a valorização cultural do trabalho. Franca sempre legitimou o uso de mão-de-obra infantil como forma de ajuda financeira ou mesmo opção para que as crianças não permanecessem na rua. Ainda hoje, um grande número de pessoas admite que é melhor a criança trabalhar, aprender qualquer tipo de serviço do que ficar sem ocupação, difundindo a idéia de que o trabalho, por mais aviltante, desumano, mal remunerado que seja, dignifica o ser humano $e$ permite às crianças $e$ aos adolescentes uma oportunidade melhor, tornando-se "a escola da vida".

Um terceiro motivo, não menos importante, é a ausência de políticas públicas de defesa, construção e proteção das crianças $e$ adolescentes. Os gestores públicos parecem não estar atentos ao desenvolvimento do lúdico, do lazer, da aprendizagem, da formação profissional das crianças. Uma sociedade que não cuida de suas crianças e adolescentes coloca-os à margem e facilita a decisão das famílias em optarem pelo trabalho, que aparece no imaginário social como dignificante $e$ formador de cidadãos para o futuro. Finalmente, a reestruturação produtiva, que acabou com os direitos sociais e trabalhistas, facilitou enormemente a inclusão do segmento infantil em "bancas de pespontos" em meados dos anos 80. Hoje, a forma de utilização se dá com do trabalho dentro da própria residência, mas a exploração continua bastante acentuada.

Apesar da persistência da utilização de mão-de-obra no município em Franca, algumas mudanças essenciais foram realizadas com o desenvolvimento de ações realizadas por diversos atores sociais na luta pelo combate ao trabalho infantil, particularmente a atuação da parceria IPEC/UNICEF.

Os êxitos do IPEC/Franca podem ser sentidos na mobilização social em torno do tema - tanto para a OIT, cujo 
objetivo inicial era realizar um raio-x do Brasil - como para o Sindicato dos Trabalhadores das Indústrias de Calçados de Franca, propiciando o conhecimento da realidade do município. Entretanto, o Programa demonstrou-se insuficiente para responder às demandas geradas posteriormente, pois quando a comunidade percebeu a ocorrência real do problema e suas conseqüências o Programa já havia se retirado, permanecendo apenas seus desdobramentos.

Ainda assim, a avaliação do Programa no município de Franca é positiva, na medida em que propiciou o aumento do número dos atores sociais e de entidades envolvidas com a questão do combate ao trabalho infantil e da exploração do trabalho dos adolescentes e agiu como catalisador de interesses das forças sociais preexistentes que propugnavam pelo combate ao trabalho da criança. Nesse sentido, o Programa pode ser considerado um marco nacional, pois conseguiu unir e organizar os agentes mobilizadores em prol do tema, resultando em uma ação conjunta de atuação e no combate progressivo do uso da mão-de-obra infantil.

Da mesma forma, a partir dessas ações cooperativas, a atuação do IPEC mudou a forma de agir e pensar o trabalho infantil em Franca - e talvez no país -, "desnaturalizando" o que era considerado "normal" e alterando a percepção dos principais agentes transformadores: criança, família e empresários. Apesar de ainda persistir a ocorrência do uso do trabalho infantil no município, instaurou-se um processo novo na defesa da criança $e$ do adolescente.

Nesse processo, a maioria das crianças pertencente às famílias pobres, particularmente as que não recebem nenhum tipo de auxílio financeiro, geralmente trabalha nas mais diversas funções, com uma jornada árdua e salários ínfimos; mães e pais inserem seus/uas filhos/as no mercado de trabalho para aumentar o orçamento doméstico, independente de ser menino ou menina. As distinções de gênero aparecem nas funções que as crianças exercem fora do trabalho contratado pelas empresas. Ressalto que 
Trabalho infantil em Franca

existe uma grande diferença entre pais/mães atendidos por programas sociais em relação aos não atendidos, o que remete à importância da conscientização social e denúncia de exploração do trabalho infantil. Sem essas duas vertentes, dificilmente haverá erradicação do trabalho da criança. 